This work is licensed under a Creative Commons Attribution 3.0 License.

\title{
A key to the genera of Issini (Hemiptera: Fulgoromorpha: Issidae) of China and neighbouring countries, with descriptions of a new genus and two new species
}

\author{
Rui MENG ${ }^{1}$, Yinglun WANG ${ }^{2, *}$ \& Daozheng QIN ${ }^{3, *}$ \\ 1,2,3 Key Laboratory of Plant Protection Resources and Pest Management of the Ministry of Education; \\ Entomological Museum, Northwest A\&F University, Yangling, Shaanxi 712100, China. \\ *Corresponding authors: yinglunw@nwsuaf.edu.cn; qindaozh@,nwsuaf.edu.cn \\ ${ }^{1}$ mengrui@nwsuaf.edu.cn \\ ${ }^{1}$ urn:1sid:zoobank.org:author:AB10C4C0-C7EE-42CF-BEC3-3022BCBA0B6D \\ ${ }^{2}$ urn:Isid:zoobank.org:author:28DCD16E-8766-4AF6-A304-C6BA463C6875 \\ ${ }^{3}$ urn:lsid:zoobank.org:author:D1AD04B9-278B-4B3D-B294-DCE0ED658D99
}

\begin{abstract}
A new genus in the tribe Issini (Hemiptera: Fulgoromorpha: Issidae) is described from South China: Orbita Meng \& Wang, gen. nov., its type species Orbita parallelodroma Meng \& Wang, gen. et sp. nov. (China: Fujian) is described and illustrated. In addition, one new species of Neokodaiana Yang, $N$. minensis sp. nov. is described and illustrated from the same locality as the new genus. A key to the genera of Issini from China and neighbouring countries is provided.
\end{abstract}

Key words. Fulgoroidea, taxonomy, Neokodaiana, gen. nov., sp. nov.

Meng R., Wang Y. \& Qin D. 2016. A key to the genera of Issini (Hemiptera: Fulgoromorpha: Issidae) of China and neighbouring countries, with descriptions of a new genus and two new species. European Journal of Taxonomy 181: 1-25. http://dx.doi.org/10.5852/ejt.2016.181

\section{Introduction}

The tribe Issini Spinola, 1839 is the largest group in the family Issidae, including 134 genera with 712 species distributed worldwide (Gnezdilov 2013a; Chen et al. 2014; Bourgoin 2015). This tribe can be diagnosed by the following characters: body ovate, head without proboscis on the frons and postclypeus, frontoclypeal suture arched or almost straight, pronotum with large disc and narrow lateral lobes, hind margin almost straight, tegmen usually not hemispherical, with distinct veins and claval suture, hind wing well-developed and very often also rudimentary, bi- or trilobed, and hind tibia usually with two lateral spines, sometimes without lateral spines.

Issini species from China were initially described by Walker (1851) from Hong Kong: Issus quadriguttatus Walker, 1851 = Issus coleoptratus (Fabricius, 1781) (this species may be an error label in Hong Kong according to Gnezdilov et al. 2004), Issus biplaga Walker, 1851 = Thabena biplaga (Walker, 1851). This tribe in the Chinese fauna was studied thereafter by Schumacher (1915), Matsumura $(1916,1938)$, 
Eskai (1931), Kato (1933), Jacobi (1944), Fennah (1956), Chou et al. (1985) and Chan \& Yang (1994). Recently, Gnezdilov (2009) and Gnezdilov \& Hayashi (2013) proposed two junior synonymies (Okissus Matsumura, 1916 = Lollius Stål, 1866 and Paravindilis Yang, 1994 = Sarimodes Matsumura, 1916), respectively; Gnezdilov \& Wilson (2006) transferred Pterilia Stål, 1859 to the Caliscelidae and without occurrences in China; Che et al. (2011, 2012), Meng \& Wang (2012) and Chen et al. (2014) added four genera and nine species to this tribe, and the latter reinstated the genus Gelastyrella Yang, 1994, mainly according to unique characteristics of male and female genitalia.

Currently, 17 genera and 65 species of Issini were recorded in China, mostly in southern China. However, the distribution of Issini remains poorly studied. In the present paper, a new genus and species are added to this tribe: Orbita parallelodroma Meng \& Wang, gen. et sp. nov. from Fujian Province in South China. A new species of Neokodaiana Yang, 1994 is also described and illustrated from the same locality as $O$. parallelodroma gen. et sp. nov. A key to the genera of Issini from China and neighbouring countries is provided below, it includes 18 genera recorded from China and six genera (Vishnuloka Distant, 1906; Jagannata Distant, 1906; Euxaldar Fennah, 1978; Darwallia Gnezdilov, 2010; Tapirissus Gnezdilov, 2014; Dactylissus Gnezdilov \& Bourgoin, 2014) from Vietnam, Laos and Myanmar. The genus Neohemisphaerius Chen, Zhang \& Chang, 2014 is also listed in this key for its tegmen has distinct claval suture as the tribe Issini, although it was originally inculded in the tribe Hemisphaerini Melichar, 1906 (Chen et al. 2014).

\section{Materials and methods}

The external morphology was observed under a Leica MZ 125 microscope. All measurements are in millimeters (mm). The terminology used for the external morphology follows Chan \& Yang (1994), the forewing venation pattern follows Bourgoin et al. (2014), "paradiscal fields of pronotum" follows Anufriev \& Emeljanov (1988) and "hypocostal plate of fore wing" follows Emeljanov (1971). The terminology of the male genitalia follows Gnezdilov et al. (2014b), female genitalia mainly follows Bourgoin (1993). The genital segments of the examined specimens were dissected and boiled in 10\% $\mathrm{NaOH}$ solution for about 2-3 minutes and subsequently transferred into glycerin. Photographs of the specimens were made using a Leica M205A microscope with a Leica DFC Camera. Images were produced using the software version LAS (Leica Application Suite) V3.7. Two females of Neokodaiana minensis Meng \& Qin sp. nov. are deposited in the Entomological Museum of Northwest Agriculture and Forestry University (NWAFU), Yangling, China, and all other specimens were borrowed from the Department of Entomology, China Agricultural University (CAU).

The measurements were mainly taken after Constant (2004) and the following abbreviations are used:
$\mathrm{BA}=$ breadth of anal tube
$\mathrm{BF}=$ breadth of the frons
$\mathrm{BV}=$ breadth of vertex
$\mathrm{BT}=$ breadth of thorax
$\mathrm{BTg}=$ breadth of the tegmen
$\mathrm{LA}=$ length of anal tube
$\mathrm{LF}=$ length of the frons
$\mathrm{LV}=$ length of vertex
$\mathrm{LP}=$ length of pronotum
$\mathrm{LM}=$ length of mesonotum
$\mathrm{LTg}=$ length of the tegmen
$\mathrm{TL}=$ total length 
MENG R. et al., Key to Issini of China and neighbouring countries

\title{
Results
}

\author{
Class Hexapoda Blainville, 1816 \\ Order Hemiptera Linnaeus, 1758 \\ Suborder Auchenorrhyncha Duméril, 1806 \\ Infraorder Fulgoromorpha Evans, 1946 \\ Superfamily Fulgoroidea Latreille, 1807 \\ Family Issidae Spinola, 1839
}

Tribe Issini Spinola, 1839

\section{Key to Issini genera of China and neighbouring countries:}

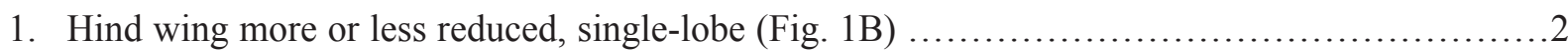

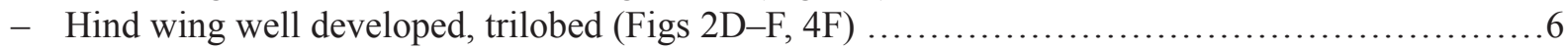

2. Postclypeus expanded into a short nasale (Fig. 3B) .........................................

- Postclypeus flattened, not expanded into short nasale .....................................

3. Frons elongate (Gnezdilov 2014: fig. 1C-D), hind tibia distally with a single lateral spine Tapirissus Gnezdilov, 2014

- Frons slightly wider than long (Fig. 3A), hind tibia with two lateral spines ...Eusudasina Yang, 1994

4. Tegmen with longitudinal veins indistinct, hind wing slighty shorter than tegmen .............5

- Tegmen with longitudinal veins distinct, hind wing tiny (Fig. 1A-B; Gnezdilov et al. 2014b: pl. 23,

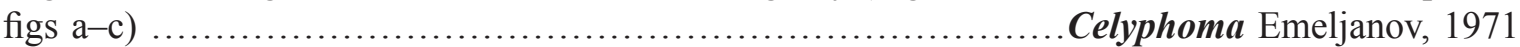

5. Frons with a row of submarginal pustules laterally, median carina absent (Gnezdilov \& Constant 2012: figs 7-9)

Euxaldar Fennah, 1978

- Frons smooth, without pustules laterally, median carina distinct (Chen et al. 2014: figs 2-35E, 2-36E) .Neohemisphaerius Chen, Zhang \& Chang, 2014

6. Vertex or frons distinctly protuberant forward, approximately triangular .......................

- Vertex and frons not protuberant forward, nearly quadrangular ............................. 9

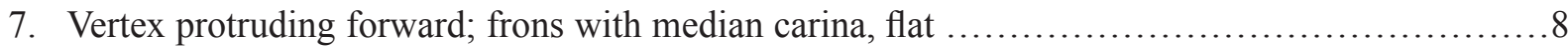

- Vertex transverse, frons with no median carina, protruding like a cone in its upper part (Gnezdilov 2012: fig. $1 \mathrm{~A}-\mathrm{C})$ Vishnuloka Distant, 1906

8. Vertex more than 3.0 times longer than wide, apex upcurved (Fig. 1C)

Pseudochoutagus Che, Zhang \& Wang, 2011

- Vertex less than 2.0 times longer than wide in midline, apex nearly horizontal (Fig. 1E)

Macrodarumoides Che, Zhang \& Wang, 2012

9. Hind wing with anal lobe rudimentary (Fig. 2E), or vannus and anal lobe both reduced, $\mathrm{CuA} 2$ and $\mathrm{CuP}$ not fused and thickened at apex (Fig. 2F) ..................................... 10

- Hind wing with vannus and anal lobe both well-developed, $\mathrm{CuA} 2$ and $\mathrm{CuP}$ fused and thickened at apex (Fig. 4F)

10. Hind wing with anal lobe very small, remigium and vannus well-developed, separated by deep cleft, veins reticulate (Fig. 2E); frons with transverse carina below upper margin (Fig. 3C) ......11

- Hind wing with vannus and anal lobe small, separated with vannus by relatively shallowly cleft, veins not reticulate (Figs 2F, 7B); frons without such transverse carina 
11. First metatarsomere with more than 35 intermediate spines; suspensorium large, nearly reaching to the apex of phallobase; the base of ventral margin of phallobase strongly angulately convex

Gelastyrella Yang, 1994

- First metatarsomere with 8-10 intermediate spines; suspensorium small, situated at base of aedeagus; the base of ventral margin of phallobase not convex (Gnezdilov 2009: figs 1-3)

Thabena Stål, 1866

12. Frons with distinct sublateral carinae crossed with feeble median carina far below upper margin, nearly rectangularly enlarged above clypeus, the transverse border lined with white and ridged, the upper line in middle of frons and the lower line above frontoclypeal suture (Fig. 6C)

- Frons without such sublateral carinae and white ridged lines Neokodaiana Yang, 1994



Fig. 1. A. Celyphoma quadrupla Meng \& Wang, 2012, holotype, $\partial^{\lambda}$, habitus, dorsal view. B. Same, lateral view. - C. Pseudochoutagus curvativus Che, Zhang \& Wang, 2011, holotype, $\hat{\jmath}$, habitus, dorsal view. - D. Macrodarumoides petalinus Che, Zhang \& Wang, 2012, holotype, Ô, frons and clypeus. E. Same, dorsal view. Scale bars $=1 \mathrm{~mm}$. 
MENG R. et al., Key to Issini of China and neighbouring countries

13. Genital style with a large hooked process below capitulum of style; aedeagus with two pairs of ventral hooks; lateral lobe of phallobase blunt at apex, lateral margin dentate in ventral view (Fig. 3E-G)

Dentatissus Chen, Zhang \& Chang, 2014

- Genital style without such process, aedeagus with a pair of ventral hooks, lateral lobe of phallobase with apex extended to spinal process curved cephalad, lateral marign smooth (Fig. 3H-I)

Kodaianella Fennah, 1956

14. Frons and clypeus with strong median carina (Gnezdilov et al. 2015: fig. 21) ......Tetrica Stål, 1866

- Frons with long or short median carina, clypeus without median carina

15. Tegmen with Sc fusing with R slightly basad of wing mid-point, forming a loop (Fig. 2A; Gnezdilov 2013b: fig. 3)

Sarima Melichar, 1903

- Tegmen without such loop vein

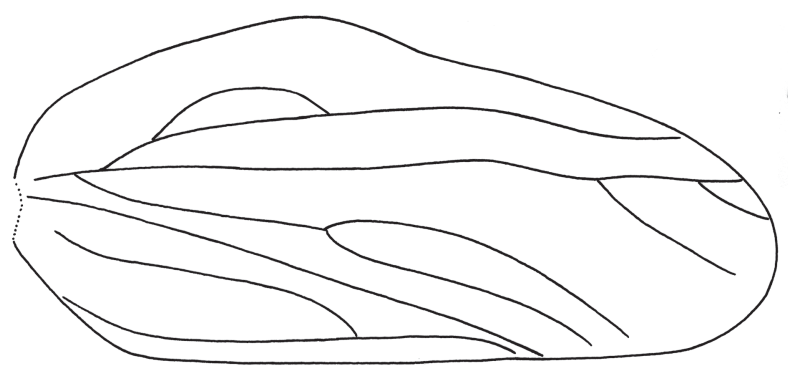

A
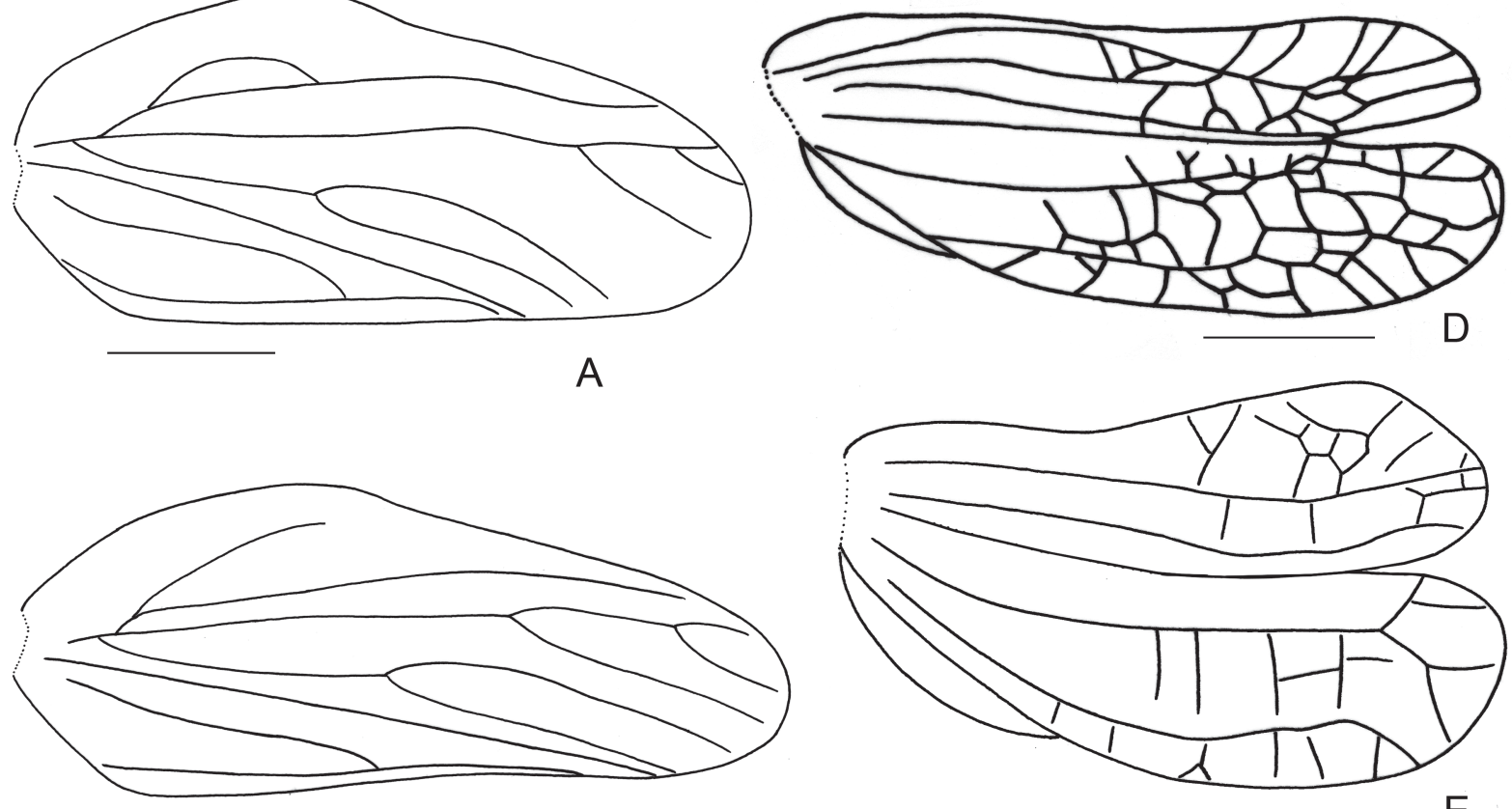

B
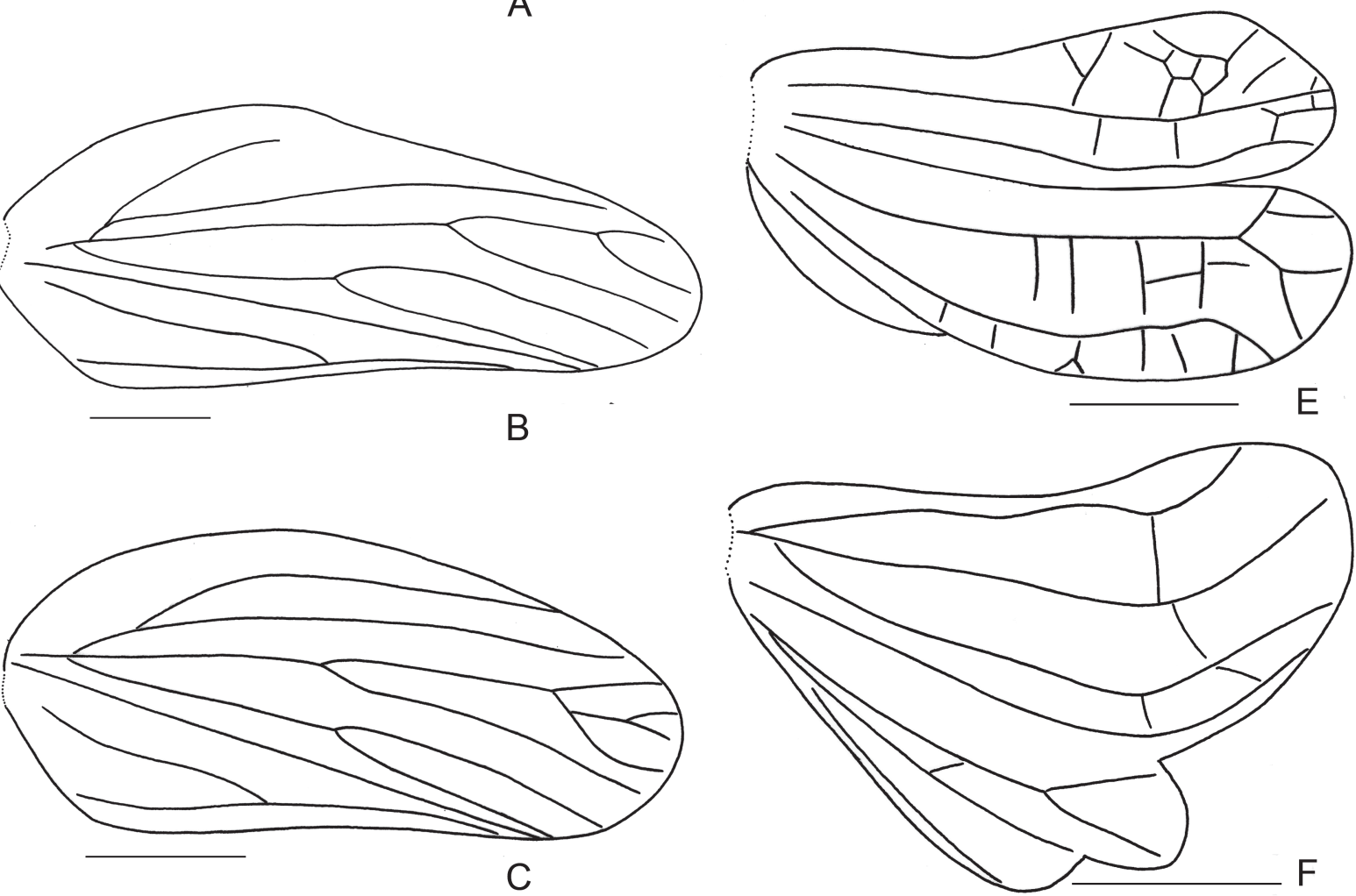

Fig. 2. Tegmen. A. Sarima sp. B. Sarimodes sp. C. Eusarima sp. - Hind wing. D. Macrodarumoides petalinus Che, Zhang \& Wang, 2012, holotype. E. Gelastyrella litaoensis Yang, 1994. F. Dentatissus damnosus (Chou \& Lu, 1985). Scale bars $=1 \mathrm{~mm}$. 


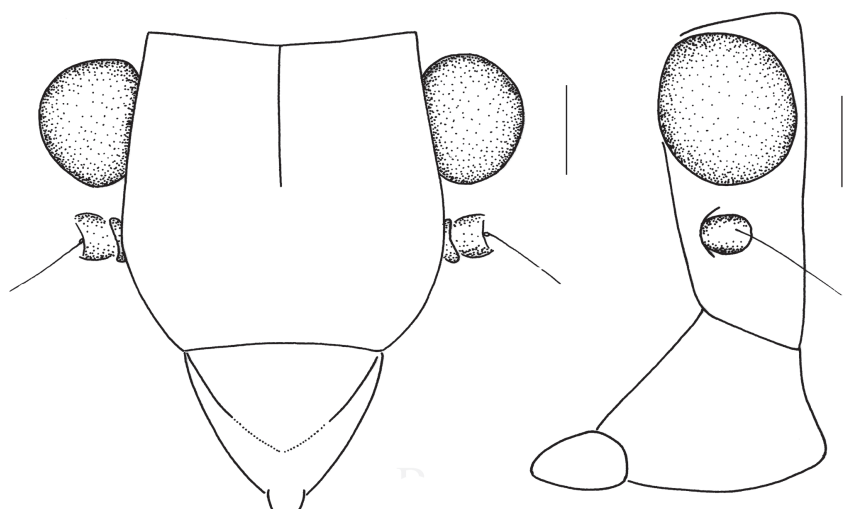

A
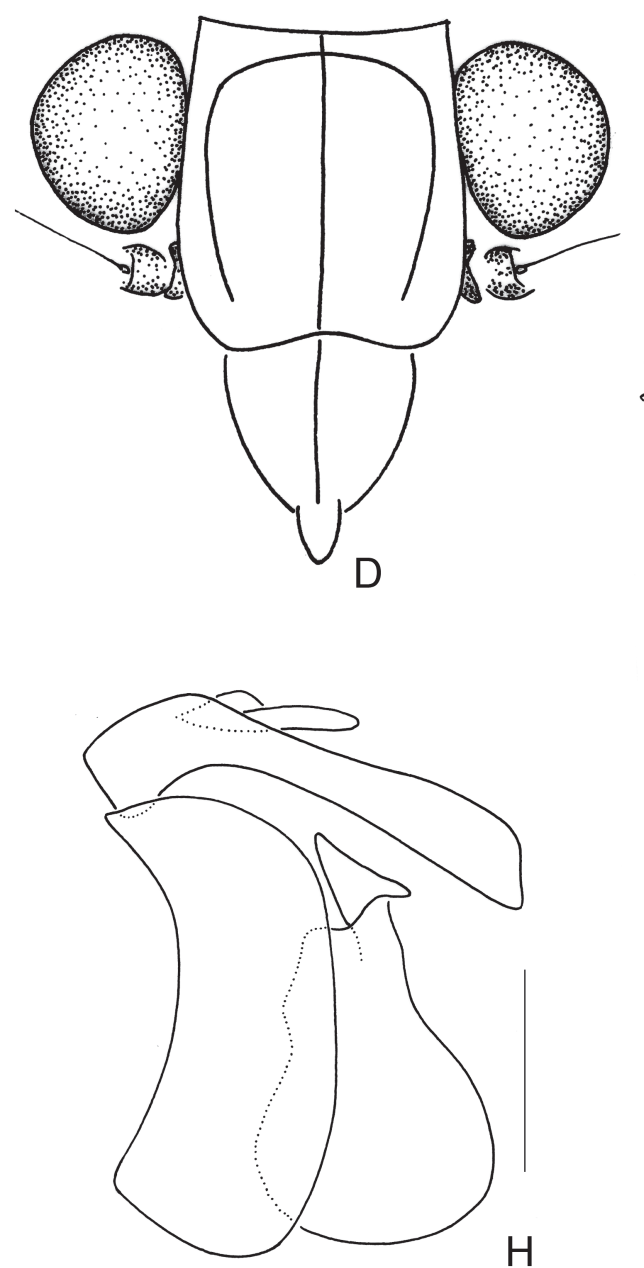

$\mathrm{H}$
B

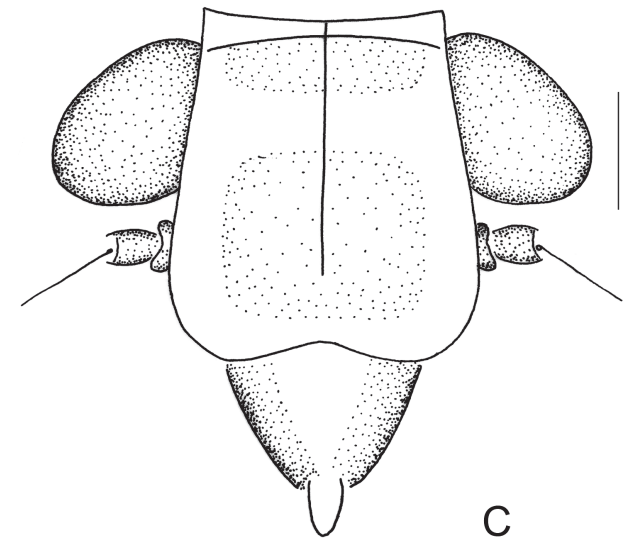

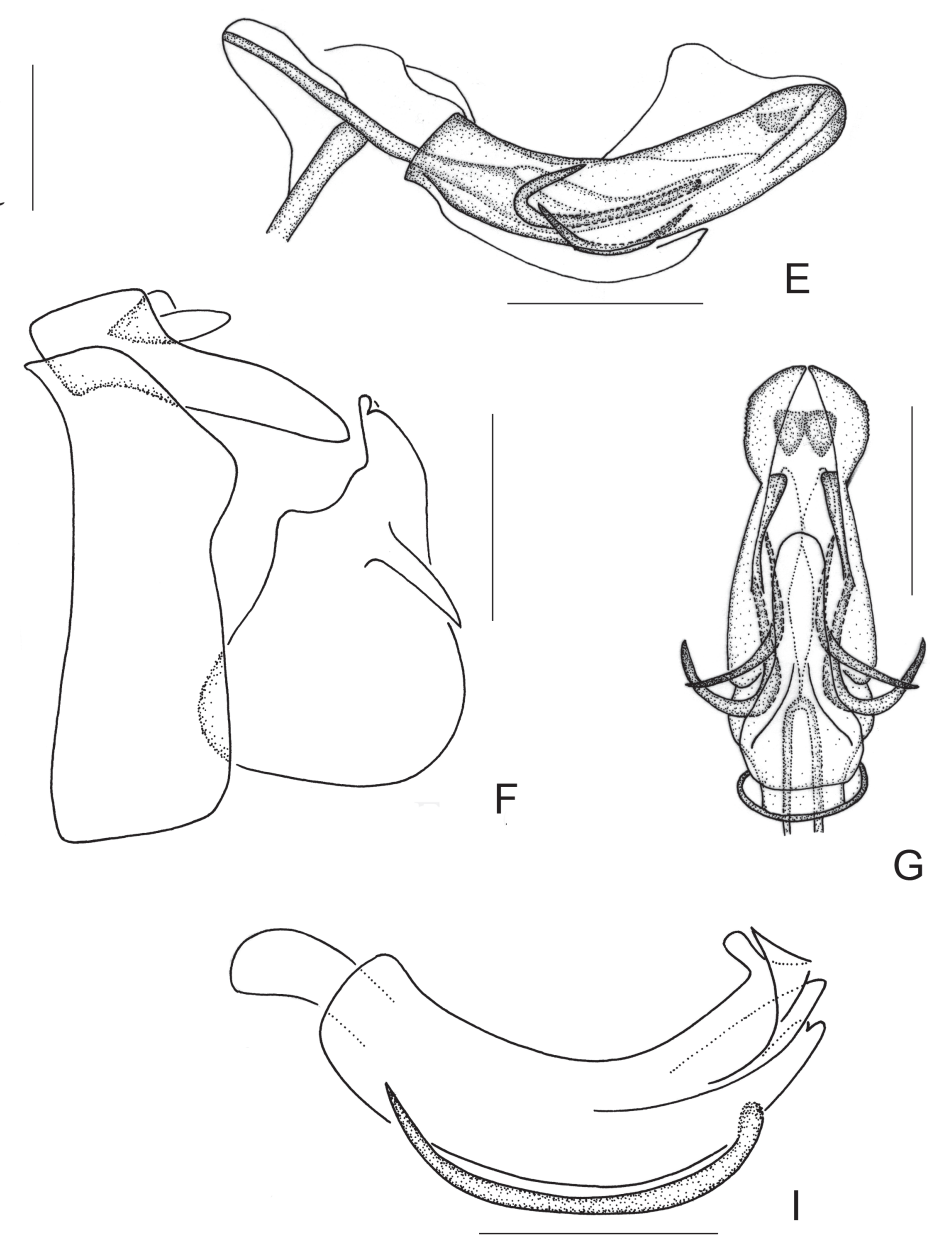

Fig. 3. - A. Eusudasina nantouense Yang, 1994, frons and clypeus. B. Same, lateral view. C. Gelastyrella litaoensis Yang, 1994, frons and clypeus. - D. Eusarima sp., frons and clypeus. E. Dentatissus damnosus (Chou \& Lu, 1985), penis, left view. F. Same, male genitalia, lateral view. G. Same, penis, ventral view. - H. Kodaianella bicinctifrons Fennah, 1956, male genitalia, lateral view. I. As previous, penis, left view. Scale bars $=0.5 \mathrm{~mm}$. 
MENG R. et al., Key to Issini of China and neighbouring countries

16. Tegmen with ScP short, not reaching beyond midlength of tegmen (Fig. 2B) .17

- Tegmen with ScP long, distinctly reaching beyond midlength of tegmen (Fig. 2C) ... .22

17. Frons with sublateral carinae crossing distinct Sinesarima Yang, 1994

- Frons with sublateral carinae absent or feeble

18. Tegmen with MP branched near apical 1/3, well beyond the furcation of $\mathrm{CuA}$ (Fig. 2B)

Sarimodes Matsumura, 1916

- Tegmen with MP branched near middle before the furcation of $\mathrm{CuA}$

19. Aedeagus with long ventral hooks

Neosarima Yang, 1994

- Aedeagus without long ventral hooks

20. Frons with feeble sublateral carinae (Chen et al. 2014: fig. 2-82E)

Yangissus Chen, Zhang \& Chang, 2014

- Frons without sublateral carinae (Fig. 4C)

21. Tegmen with hypocostal plate

Dactylissus Gnezdilov \& Bourgoin, 2014

- Tegmen without hypocostal plate (Fig. 4D) Orbita Meng \& Wang, gen. nov.

22. Frons almost twice longer than wide; clypeus with lower part of postclypeus and anteclypeus with median triangular projection (Gnezdilov 2014: figs 4-5) ........Darwallia Gnezdilov, 2010

- Frons slightly wider than long; clypeus flattened, without such projection .23

23. Vertex a little longer than wide; frons with obscure median carina Jagannata Distant, 1906

- Vertex distinctly wider than long; frons clearly tricarinate .24

24. Frons with median carina and sublateral carinae present at basal half, slightly above middle, indistinctly transversely elevated on the surface (Chan \& Yang 1994: fig. 39B) ........Parasarima Yang, 1994

- Frons with distinct median and sublateral carinae, reaching over middle, flattened on the surface (Fig. 3D)

Eusarima Yang, 1994

\section{Diagnoses for genera in the key}

A short diagnosis for each genus, except for the new genus in the key, is provided below. We follow the definition of these genera from the original description, in combination with their respective redescriptions in the latest literature, which results in the following distinctive set of features:

\section{Celyphoma Emeljanov, 1971}

Celyphoma Emeljanov, 1971: 625 (type species: Celyphoma fruticulina Emeljanov, 1971, by original designation).

\section{Diagnosis}

The genus can be recognized by the following characters: small sized; vertex distinctly wider than long; frons elongate, with median carina, upper margin arcuate or slightly concave; mesonotum with inverted V or Y-shaped carina at middle; hind wing rudimentary; hind tibia with 1-2 lateral spines; phallobase with one or two pairs of lateral processes, aedeagus with pair of ventral processes. 
Dactylissus Gnezdilov \& Bourgoin, 2014

Dactylissus Gnezdilov \& Bourgoin in Gnezdilov et al., 2014a: 86 (type species: Dactylissus armillarius Gnezdilov \& Soulier-Perkins, 2014, by original designation).

\section{Diagnosis}

The genus can be recognized by the following characters: medium-sized; vertex twice as wide as long medially, without median carina; frons wide, median carina not reaching frontoclypeal suture; tegmen elongate, with narrow hypocostal plate; Sc short, not reaching over middle; hind wing trilobed; hind margin of female sternum VII convex medially.

Darwallia Gnezdilov, 2010

Darwallia Gnezdilov, 2010: 43 (type species: Issus patulus Walker, 1857, by original designation).

\section{Diagnosis}

The genus can be recognized by the following characters: medium to large-sized; vertex elongate, lateral margins keel-shaped; frons narrow, weakly enlarged above clypeus, with median carina; lower part of postclypeus and anteclypeus with median triangular projection; tegmen broad, without hypocostal plate; hind wing trilobed; each dorsolateral phallobase lobe with large, nearly triangular, serrated subapical process; aedeagus with pair of long acuminate ventral hooks.

Dentatissus Chen, Zhang \& Chang, 2014

Dentatissus Chen, Zhang \& Chang, 2014: 140 (type species: Dentatissus brachys Chen, Zhang \& Chang, 2014, by original designation).

\section{Diagnosis}

The genus can be recognized by the following characters: medium-sized; frons broad, median carina present in basal half, with a line of verrucae along lateral margin on each side; hindwing trilobed, vannus and anal lobe small; genital style with large long process at base of capitulum; dorsal lobe of phallobase membranaceous, aedeagus with two pairs of ventral processes.

Eusarima Yang, 1994

Eusarima Yang in Chan \& Yang, 1994: 108 (type species: Eusarima contorta Yang, 1994, by original designation).

\section{Diagnosis}

The genus can be recognized by the following characters: medium-sized; vertex 1.6-2.0 times wider than long; frons shortly ampliated, median and sublateral carinae distinct, reaching over middle, sublateral carinae cross median carina below apical margin of vertex; tegmen elongate, Sc long, reaching over middle; phallobase with lateral lobes pigmented, usually short; aedeagus with a pair of processes, directed cephalad.

Eusudasina Yang, 1994

Eusudasina Yang in Chan \& Yang, 1994: 81 (type species: Eusudasina nantouensis Yang, 1994, by original designation). 
MENG R. et al., Key to Issini of China and neighbouring countries

\section{Diagnosis}

The genus can be recognized by the following characters: medium-sized, body hemispherical; vertex three times wider than long; frons slightly wider than long, median carina present in basal half; postclypeus right angulate in lateral view; tegmen with longitudinal veins indistinct, densely reticulate, clavus reaching over middle of tegmen; hind wing tiny.

Euxaldar Fennah, 1978

Euxaldar Fennah, 1978: 61 (type species: Euxaldar jehucal Fennah, 1978, by original designation).

\section{Diagnosis}

The genus can be recognized by the following characters: medium-sized; vertex about three times wider than long; frons longer than broad, disc finely granulate, with a row of submarginal pustules laterally on each side; postclypeus roundly curved in lateral view; tegmen with claval suture distinct, claval veins uniting distad of middle of clavus; hind wing more than half length of tegmen, veins reticulate.

Gelastyrella Yang, 1994

Gelastyrella Yang in Chan \& Yang, 1994: 90 (type species: Gelastyrella litaoensis Yang, 1994).

Gelastyrella - Chen et al. 2014: 131

\section{Diagnosis}

The genus can be recognized by the following characters: medium to large-sized; vertex wider than long, anterior margin rounded; frons as long in middle line as wide at widest part, median carina distinct, median and transverse sublateral carinae joined below vertex; hind wing trilobed, veins reticulate, anal lobe rudimentary; first metatarsomere with more than 35 intermediate spines; suspensorium large, nearly reaching to the apex of phallobase, phallobase at base angulately convex on ventral side.

Jagannata Distant, 1906

Jagannata Distant, 1906: 338 (type species: Jagannata chelonia Distant, 1906, by original designation).

\section{Diagnosis}

The genus can be recognized by the following characters: medium-sized; vertex a little longer than wide, anterior margin angularly produced; frons as long in middle line as wide at widest part, median carina indistinct; tegmen elongate, Sc long, reaching over middle; hind wing well-developed.

Kodaianella Fennah, 1956

Kodaianella Fennah, 1956: 508 (type species: Kodaianella bicinctifrons Fennah, 1956, by original designation).

Kodaianella - Gnezdilov 2013c: 42. — Chen et al. 2014: 136.

\section{Diagnosis}

The genus can be recognized by the following characters: small to medium-sized; vertex transverse, nearly twice as wide as long medially; frons wide, with median carina distinct only, not reaching frontoclypeal suture; hind wing trilobed, with vannus and anal lobe rudimentary; genital style with a 
round process under capitulum; phallobase with pair of subapical processes laterally, aedeagus with a pair of ventral hooks.

Macrodarumoides Che, Zhang \& Wang, 2012

Macrodarumoides Che, Zhang \& Wang, 2012: 52 (type species: Macrodarumoides petalinus Che, Zhang \& Wang, 2012, by original designation).

\section{Diagnosis}

The genus can be recognized by the following characters: medium to large-sized; vertex elongate, approximately triangular; frons long and nearly triangular, median carina present; clypeus elevated with central carina; tegmen with longitudinal veins prominent, $\mathrm{CuA}$ simple; hind wing trilobed, veins reticulate, anal lobe rudimentary.

Neohemisphaerius Chen, Zhang \& Chang, 2014

Neohemisphaerius Chen, Zhang \& Chang, 2014: 80 (type species: Neohemisphaerius wugangensis Chen, Zhang \& Chang, 2014, by original designation).

\section{Diagnosis}

The genus can be recognized by the following characters: medium-sized, body smooth and shiny, hemispherical; vertex 2.5-2.7 times wider than long; frons long, with median carina; clypeus convex centrally, sloped at basal one third; tegmen hemispherical, claval suture present; hind wing rudimentary, less than half length of tegmen, veins simple.

Neokodaiana Yang, 1994

Neokodaiana Yang in Chan \& Yang, 1994: 92 (type species: Neokodaiana chihpenensis Yang, 1994, by original designation).

\section{Diagnosis}

The genus can be recognized by the following characters: medium-sized; vertex three times wider than long in midline; frons more than 2.0 times wider than long, median carina feeble, sublateral carinae far below anterior margin of vertex, disc convex; hind wings trilobed, vannus and anal lobe reduced; aedeagus with lateral phallobasal lobes dentate dorsally near apex, with large lobe-like processes laterally and a pair of hooks ventrally.

Neosarima Yang, 1994

Neosarima Yang in Chan \& Yang, 1994: 104 (type species: Neosarima niqra Yang, 1994, by original designation).

\section{Diagnosis}

The genus can be recognized by the following characters: medium to large-sized; vertex twice as wide as long; frons shortly amplicated, median carina reaching to middle, sublateral carina feeble; tegmen elongate, Sc not reaching over middle, MP forked near middle; hind wing trilobed; aedeagus with two pairs of ventral processes, dosal one short, ventral one long. 
MENG R. et al., Key to Issini of China and neighbouring countries

Parasarima Yang, 1994

Parasarima Yang in Chan \& Yang, 1994: 95 (type species: Parasarima pallizona Yang, 1994, by original designation).

\section{Diagnosis}

The genus can be recognized by the following characters: medium-sized; vertex distinctly wider than long, median carina feeble; frons with median carinae and sublateral carinae present at upper half; tegmen with Sc long and reaching over middle; hind wing trilobed.

Pseudochoutagus Che, Zhang \& Wang, 2011

Pseudochoutagus Che, Zhang \& Wang, 2011: 63 (type species: Pseudochoutagus curvativus Che, Zhang \& Wang, 2011, by original designation).

\section{Diagnosis}

The genus can be recognized by the following characters: medium-sized; vertex more than three times longer than wide, apex upcurved; pronotum and mesonotum without median and sublateral carinae; tegmen thickly and coarsely reticulate, claval suture present; hind wing trilobed, veins reticulate, anal lobe rudimentary.

\section{Sarima Melichar, 1903}

Sarima Melichar, 1903: 78 (type species: Sarima illibata Melichar, 1903, by original designation).

Sarima - Distant 1906: 342. — Gnezdilov 2013b: 176.

\section{Diagnosis}

The genus can be recognized by the following characters: medium-sized; vertex transverse, median carina sometimes weak; frons wide, with median carina, sublateral carinae distinct only in upper half; tegmen with hypocostal plate; Sc short and fusing with R forming a loop; hind wing well three-lobed.

\section{Sarimodes Matsumura, 1916}

Sarimodes Matsumura, 1916: 115 (type species: Sarimodes taimokko Matsumura, 1916, by original designation).

Paravindilis Yang in Chan \& Yang, 1994: 94 (type species: Paravindilis taiwana Yang, 1994, by original designation), synonymised by Gnezdilov \& Hayashi 2013: 162.

\section{Diagnosis}

The genus can be recognized by the following characters: medium to large-sized; vertex slightly wider than long, with weak median carina; frons with a row of submarginal tubercules on each side, median carina short, sublateral carina indistinct; tegmen without hypocostal plate, Sc just reaching midlength of tegmen, MP forked near distal one-third of tegmen; hind wing trilobed; phallobase with dorsolateral lobe bearing a pair of strong processes apically; aedeagus with a pair of long hooks at middle.

\section{Sinesarima Yang, 1994}

Sinesarima Yang in Chan \& Yang, 1994: 99 (type species: Parasarima pannosa Yang, 1994, by original designation). 


\section{Diagnosis}

The genus can be recognized by the following characters: medium to large-sized; vertex 1.7 times wider than long, anterior margin evenly angulate; frons shortly ampliated, median carina distinct at basal third, submedian carina only distinct transversely; tegmen elongate, Sc not reaching over middle; hind wing trilobed.

Tapirissus Gnezdilov, 2014

Tapirissus Gnezdilov, 2014: 762 (type species: Tapirissus guilberti Gnezdilov, 2014, by original designation).

\section{Diagnosis}

The genus can be recognized by the following characters: medium-sized; frons elongate and wholly visible from above, sublateral carinae absent, frons and vertex joined at obtuse angle; postclypeus large, in shape of flattened laterally proboscis bearing a median carina, resembling a chisel; tegmen with reticulate venation and without hypocostal plate; hind wing one-lobed; hind tibia distally with a single lateral spine.

Tetrica Stål, 1866

Tetrica Stål, 1866a: 208 (type species: Tetrica fusca Stål, 1866, by original designation).

Tetrica-Distant 1906: 339.

\section{Diagnosis}

The genus can be recognized by the following characters: medium-sized; vertex transverse, with median carina; frons with strong median carina which runs through it, continued through the clypeus; tegmen with wide hypocostal plate; hind wing well-developed, trilobed.

Thabena Stål, 1866

Thabena Stål, 1866a: 208 (type species: Issus retractus Walker, 1857, by subsequent designation in Stål 1866b: 393).

Cibyra Stål, 1861: 209 (preoccupied, type species: Issus testudinarius Stål, 1854 (= Issus spectans Walker, 1858), by original designation).

Gelastyra Kirkaldy, 1904: 280, new name for Cibyra Stål, 1861, synonymised by Gnezdilov 2009: 77. Borbonissus Bonfils, Attié \& Reynaud, 2001: 217 (type species: Borbonissus brunnifrons Bonfils, Attié \& Reynaud, 2001, by original designation), synonymised by Gnezdilov 2009: 77.

\section{Diagnosis}

The genus can be recognized by the following characters: medium to large-sized; frons wide with median carina crossed by transverse carina inferior to its upper margin; hind wing trilobed, veins reticulate, anal lobe rudimentary; first metatarsomere with 8-21 intermediate spines; suspensorium small, situated at base of aedeagus; ventral margin of phallobase smooth at base, aedeagus with a pair of ventral hooks.

Vishnuloka Distant, 1906

Vishnuloka Distant, 1906: 345 (type species: Vishnuloka prominula Distant, 1906, by original designation).

Delia Melichar, 1906: 265 (type species: Delia deserta Melichar, 1906), homonymy. 
MENG R. et al., Key to Issini of China and neighbouring countries

Ardelia Melichar, 1907: 324, nom. nov. pro Delia Melichar, 1906, nec Delia Robineau-Desvoidy, 1830, synonymised by Gnezdilov 2012: 240.

\section{Diagnosis}

The genus can be recognized by the following characters: large-sized; vertex transverse, anterior margin weakly marked; frons without intermediate carinae, protruding like a cone on its upper part; tegmen narrowing apically; $\mathrm{M}$ bifurcates distally, $\mathrm{CuA}$ bifurcates medially; hind wing three-lobed; first metatarsomere with two latero-apical and two intermediate spines.

Yangissus Chen, Zhang \& Chang, 2014

Yangissus Chen, Zhang \& Chang, 2014: 146 (type species: Yangissus maolanensis Chen, Zhang \& Chang, 2014, by original designation).

\section{Diagnosis}

The genus can be recognized by the following characters: medium-sized; vertex twice as wide as long; frons with median carina reaching to middle, submedian carina feeble; tegmen with Sc reaching over middle, MP and $\mathrm{CuA}$ forked near middle; hind wing trilobed; lateral lobe of phallobase with complicated processes near apex; aedeagus without ventral process.

\section{Orbita Meng \& Wang, gen. nov. urn:1sid:zoobank.org:act:7CF448F0-FFC7-4EBC-9C58-4B37082D20AB} Figs 4-5

\section{Type species}

Orbita parallelodroma Meng \& Wang, gen. et sp. nov.

\section{Diagnosis}

Orbita gen. nov. can be easily distinguished from most genera in the tribe Issini by vertex quadrangular, tegmen with $\mathrm{ScP}$ vein not reaching over middle, MP vein bifurcate near middle a little before the furcation of $\mathrm{CuA}$, hind wing well-developed trilobed and pattern of veins. Beyond these combination features, the new genus is also similar to the genera Sinesarima Yang, 1994, Neosarima Yang, 1994, Dactylissus Gnezdilov \& Bourgoin, 2014 and Yangissus Chen, Zhang \& Chang, 2014 . The new genus can be differentiated from Sinesarima and Neosarima by the particular structure of lateral phallobasal lobe and aedeagus no ventral hooks.

This new genus can be distingushed from Dactylissus by the following combination of characters (features of Dactylissus in parentheses): 1) tegmen without hypocostal plate (tegmen with narrow hypocostal plate); 2) vertex with weak median carina (vertex with no carina); 3) pygofer with hind margin concave medially (pygofer with hind margin convex medially)

The new genus differs from Yangissus in the following combination of characters (features of Yangissus in parentheses): 1) frons with distinct median carina reaching to below eyes, without sublateral carinae, lateral margin auricularly extended below antennae (frons with feeble median carina almost reaching to frontoclypeal suture, with feeble sublateral carinae, lateral margin obtusely extended below antennae); 2) hind wing without transverse veins between $\mathrm{CuP}$ and $\mathrm{Pcu}$ (hindwing with transverse veins between $\mathrm{CuP}$ and $\mathrm{Pcu}$ ); 3) pygofer with hind margin oblique and weakly convex at ventral half, caudo-dorsal angle blunt not protudent (pygofer with hind margin slightly convex medially, caudo-dorsal angle triangularly protrudent); 4) lateral lobe of phallobase becoming into processes at basal one third (lateral lobe bearing processes near apex). 


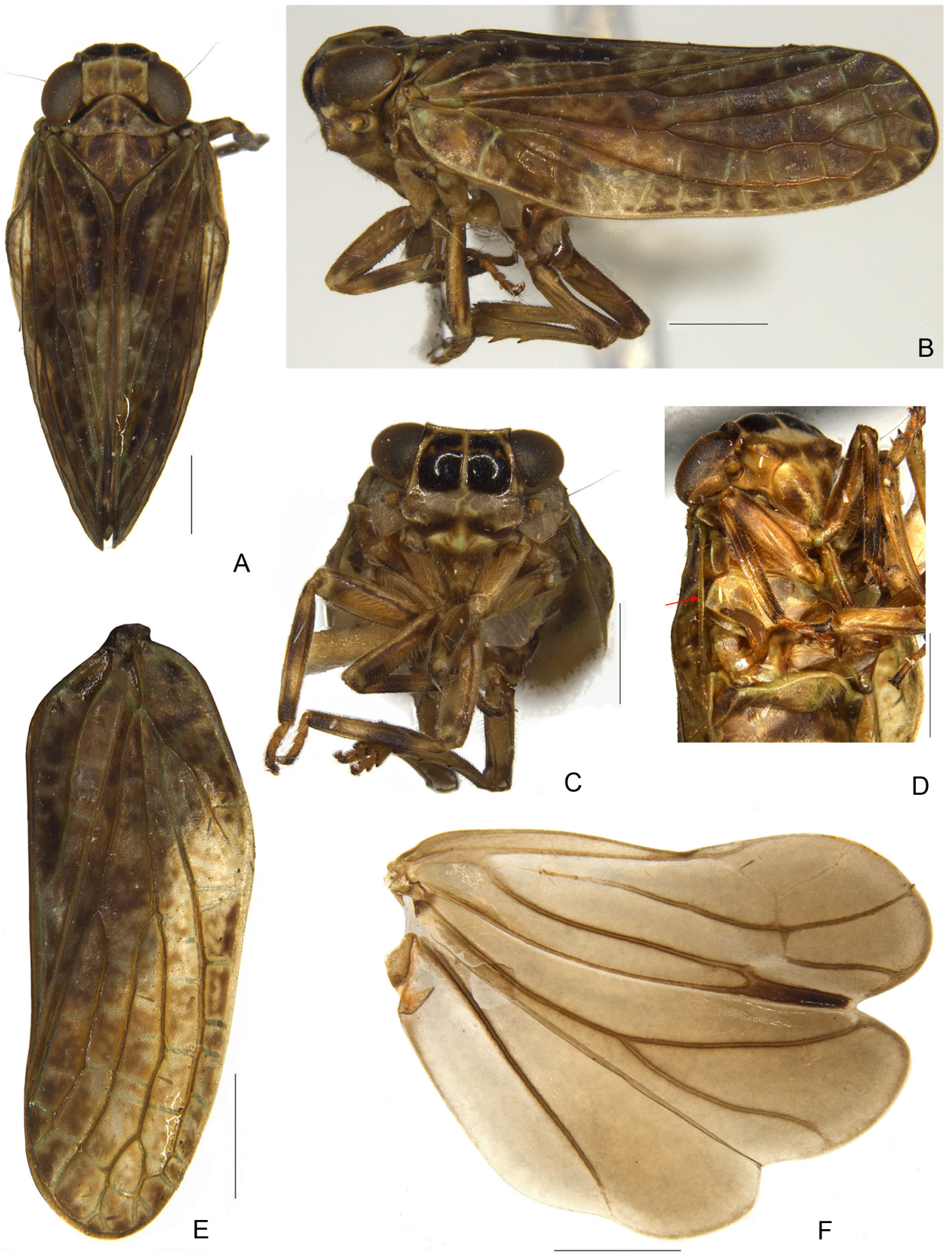

Fig. 4. Orbita parallelodroma Meng \& Wang, gen. et sp. nov., holotype. A. Habitus, dorsal view. B. Habitus, lateral view. C. Frons and clypeus. D. Head and thorax, latero-ventral view. E. Tegmen. F. Hind wing. Scale bars $=1 \mathrm{~mm}$. 
MENG R. et al., Key to Issini of China and neighbouring countries

\section{Etymology}

The generic name is derived from the orbs on the frons. The name is feminine in gender.

\section{Description}

HEAD. Vertex including eyes slightly wider than pronotum (Fig. 4A), nearly quadrangular; anterior margin convex at middle; posterior margin subangularly emarginated; all margins ridged; disc depressed; with weak median carina (Fig. 4A). Frons wider than long in middle line, gradually widening to below antennae and then abruptly incurved to frontoclypeal suture, as auricula; upper margin almost straight; disc with two large glossy orbs, depressed in middle near frontoclypeal suture, with half median carina between the two orbs (Fig. 4C). Frontoclypeal suture curved upward (Fig. 4C). Clypeus small, triangular, disc compressed (Fig. 4C). Rostrum reaching post-trochanters, apical segment shorter than subapical segment. Eyes large, reniform (Fig. 4A, C). Ocelli present. Antennae moderately short, pedicel subglobose with large sensory pits, flagellum moderately long (Fig. 4B-C).

Thorax. Pronotum almost as long as vertex in middle line, anterior margin strongly convex between eyes, posterior margin emarginate medially, median carina weak, disc smooth without any tubercula and with two pits in middle area (Fig. 4A), paradiscal fields very thin and narrow behind eyes, lateral lobes wide, lamelliform, without any ridge, ventral margin moderately oblique (Fig. 4C). Mesonotum triangular, slightly shorter than length of pronotum and vertex together; anterior margin almost straight and slightly convex at middle; with three feeble carinae (Fig. 4A).

TEGMEN. Elongate, without hypocostal plate (Fig. 4D, see the arrow); basal surface strongly elevated near costal margin, apical margin rounded; inner margin straight, postcostal area much broader than costal area, with 2-3 transverse veinlets; veins $\mathrm{ScP}+\mathrm{R}, \mathrm{MP}$ and $\mathrm{CuA}$ separated at base; veins $\mathrm{ScP}+\mathrm{R}$ forking close to basal cell; ScP not reaching beyond midlength of tegmen, very weak near costal margin; $\mathrm{R}$ simple, forked near apex, MP and CuA both forked almost at same level and slightly beyond the union of claval veins, $\mathrm{MP}_{1}+\mathrm{MP}_{2}$ forked near apex, $\mathrm{MP}_{1}$ and $\mathrm{MP}_{2}$ respectively biforked just before apex, longitudinal veins distinctly prominent and transverse veins relatively weak. Clavus long, almost reaching apex, two claval veins (Pcu and A1) united at middle of clavus (Fig. 4E).

HIND wiNG. Well developed, trilobed. Veins $\mathrm{R}$ and $\mathrm{CuA}$ each with two branches near distal part; $\mathrm{M}$ fused with $\mathrm{CuA}$ near base; A1 separated at base with posterior branch slightly weakened in comparison with the anterior branch at apex; Pcu and A1 fused in their middle section and subsequently diverging in apical part; $\mathrm{M}, \mathrm{CuP}, \mathrm{A}_{2}$ simple, between $\mathrm{R} 2$ and $\mathrm{M}$ and between $\mathrm{M}$ and $\mathrm{CuA} 1$ with single transverse vein (R 2 r-m M 1 m-cu CuA 2 CuP 1 Pcu $1 \mathrm{~A}_{1} 2 \mathrm{~A}_{2}$ 1); CuA2 and CuP fused and thickened at apex (Fig. 4F).

LEgs. Fore and median femora slightly dorso-ventrally flattened; fore and median tibiae thin; hind tibia with two or three lateral spines.

Male GenITALIA. Anal tube elongate, widest at base; lateral margin subparallel, apical margin rounded; slightly arcuately bent down near middle in lateral view; anal column very short, situated at base (Fig. 5A). Pygofer with hind margin strongly concave medially, caudo-dorsal angle blunt (Fig. 5B). Penis shallowly curved; dorso-lateral phallobase lobes separated into dorsal lobe and lateral lobe, lateral lobe fused with dorsal lobe shortly at basal one third, before and after the fused part, lateral lobe turned into a process directing cephalad and one more process directing caudad; aedeagus without ventral hooks, with a small lateral process at basal one-third (Fig. 5D-F). Genital style in lateral view with hind margin distinctly excavated at middle (Fig. 5B).

Female genitalia. Anal tube in dorsal view elongate, widest at base; lateral margin subparallel, apical margin rounded; column very short, situated at base (Fig. 5I). Gonoplac elongate, with wide membranous 


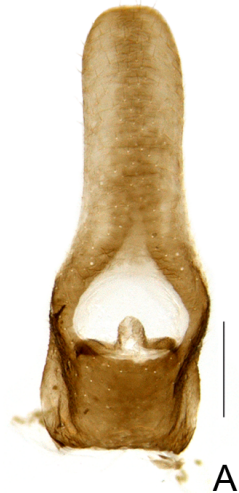

A

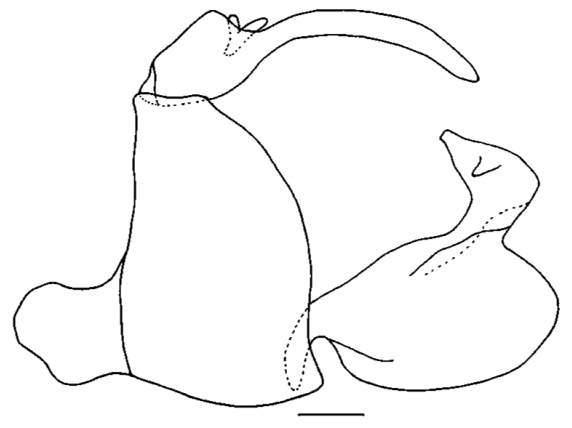

B
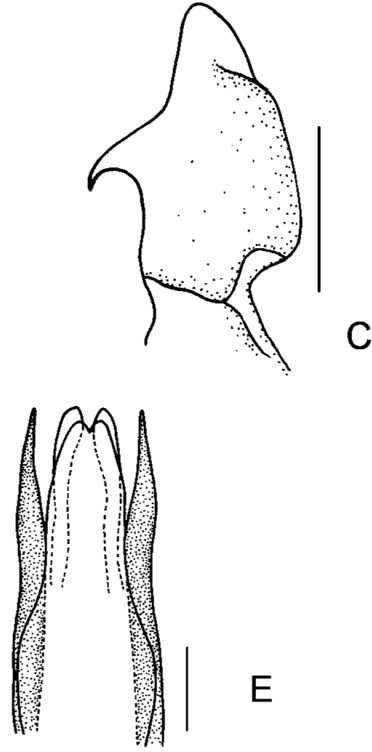

E

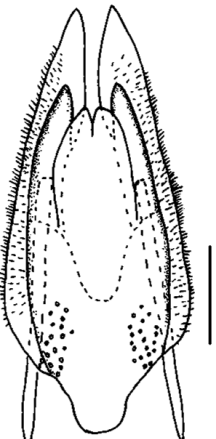

G

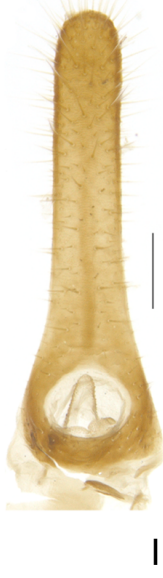

$\mathrm{H}$
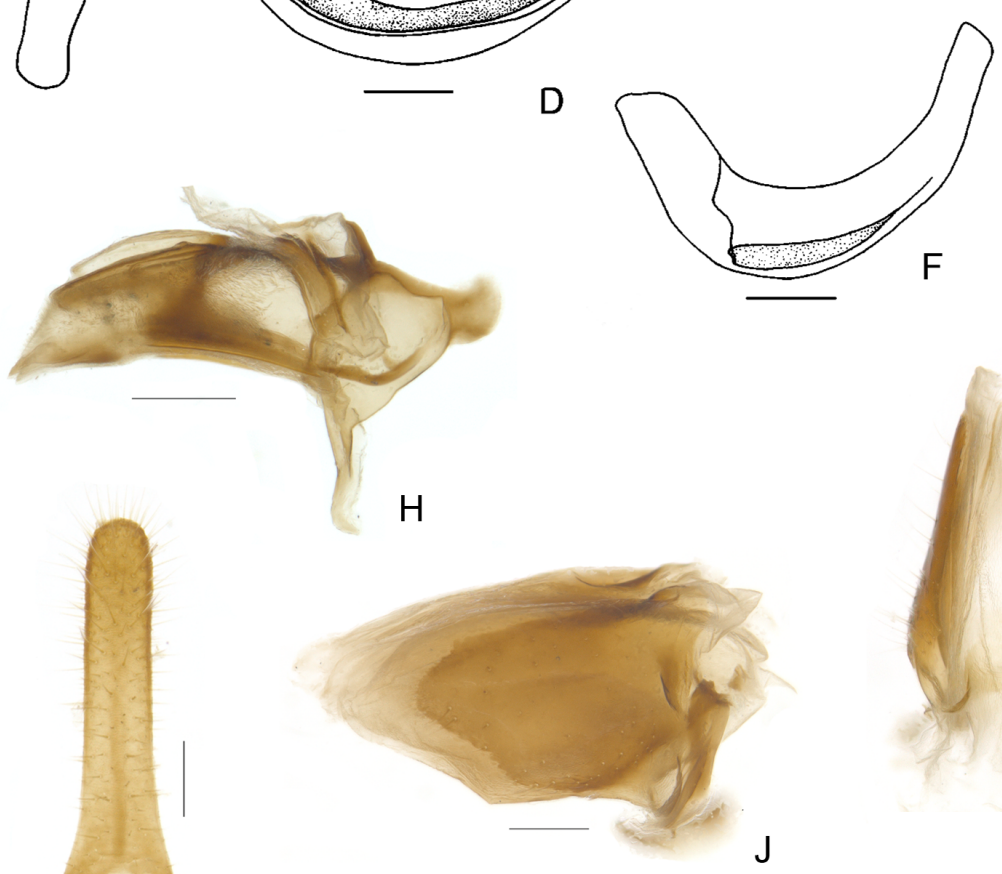

$\mathrm{J}$

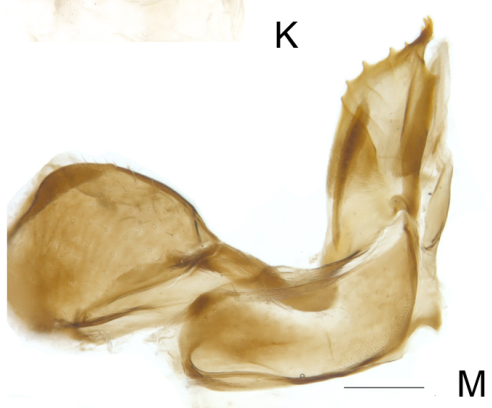

Fig. 5. Orbita parallelodroma Meng \& Wang, gen. et sp. nov. - A-F. Holotype. A. Male anal tube, dorsal view. B. Male genitalia, lateral view. C. Capitulum of style, dorsal view. D. Phallobase, left view. E. Phallobase, apical half, ventral view. F. Aedeagus, left view. - G. Gonapophyses IX and gonaspiculum bridge, dorsal view. H. Gonapophyses IX and gonaspiculum bridge, right view. I. Female anal tube, dorsal view. J. Gonoplac, left view. K. Gonoplac, dorsal view. L. Sternum VII, ventral view. M. Gonocoxa VIII and gonapophysis VIII, right view. Scale bars $=0.2 \mathrm{~mm}$. 
MENG R. et al., Key to Issini of China and neighbouring countries

near apex (Fig. 5J-K). Gonapophyses IX long, nearly ovate in dorsal view (Fig. 5G). Gonospiculum bridge moderately large, basal part nearly as long as apical part (Fig. 5H). Anterior connective laminae of gonapophysis VIII broad with three small teeth apically (Fig. 5M). Gonocoxa VIII with hind margin concave (Fig. 5M).

Size. Size of the single species hitherto recorded ranges from 5.8 to $5.9 \mathrm{~mm}$ of males, 6.2 to $6.4 \mathrm{~mm}$ of females.

\section{Distribution}

China (Fujian Province).

Orbita parallelodroma Meng \& Wang, gen. et sp. nov. urn:1sid:zoobank.org:act:A16DD267-2238-4F9C-8555-DA44D0A88D76

Figs 4-5

\section{Etymology}

The specific epithet is constituted from the ancient Greek words "parallelos" meaning parallel and "dromos" meaning running, refers to the pair of long spiniform processes of phallobasal lateral lobe directing caudad parallel to each other.

\section{Material examined}

\section{Holotype}

CHINA: Ô, Fujian Province, Dehua City, Shuikou Town, $118.4^{\circ}$ E, $25.7^{\circ} \mathrm{N}, 11$ Nov. 1974, coll. Jikun Yang.

\section{Paratypes}

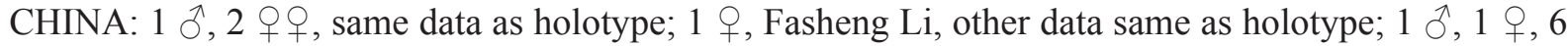
Nov. 1974, other data same as holotype; 1 , 13 Nov. 1974, other data same as holotype.

\section{Measurements and ratios}

TL: $\hat{\jmath}(\mathrm{n}=3): 5.8-5.9 \mathrm{~mm}$; + ( $(\mathrm{n}=5): 6.2-6.4 \mathrm{~mm}$; LTg: $\hat{\jmath}(\mathrm{n}=2): 4.8-4.9 \mathrm{~mm}$; + $(\mathrm{n}=2): 4.1-4.6$ $\mathrm{mm} ; \mathrm{BV} / \mathrm{LV}=2.0 ; \mathrm{BF} / \mathrm{LF}=1.3 ; \mathrm{LM} / \mathrm{LP}=2.1 ; \mathrm{BT} / \mathrm{LM}=2.1 ; \mathrm{LTg} / \mathrm{BTg}=2.9 ; \mathrm{LA} / \mathrm{BA}($ đ $)=2.7 ; \mathrm{LA} /$ $\mathrm{BA}(+)=3.3$.

\section{Description}

BoDy. Brown alternated with yellow green and fuscous.

HEAD. Vertex fulvous, with light green margins and median line (Fig. 4A). Frons fulvous with two large, black, glossy protuberances between eyes; brown transverse line near middle of orbs and yellowish green central carina, dark brown near frontoclypeal suture; margins black (Fig. 4C). Genae fawn with fuscous speckles (Fig. 4B). Clypeus dark brown near frontoclypeal suture and central fascia yellowish green (Fig. 4C). Eyes fuscous (Figs 4A-B).

Thorax. Pronotum fulvous with yellowish green median line, two fuscous pits in middle, lateral lobes brown. Mesonotum dark brown, with median line and anterior angles green; lateral area with fuscous speckles (Fig. 4A).

TEGMEN. Brown with fuscous speckles; longitudinal veins brown; transverse veins green (Fig. 4E).

HIND wING. Brown, veins fuscescent (Fig. 4F). 
LEgs. Fore and median femora fulvous with fuscous longitudinal fascia laterally and transverse stripe apically; fore and median tibiae fulvous with fuscous transverse stripes respectively at base and apex; hind femur fulvous with fuscous fascia at apex, hind tibiae fulvous, tips of teeth black. Metatibiotarsal formula $2-3+8 / 8 / 2$.

Abdomen. Dark brown.

MaLE genitalia. Dorsal phallobase lobe with a short process at apical one-third of lateral margin; lateral lobe turned into a long spiniform process directing caudad and a thick unciform process directing cephalad with apex curved caudad at basal third; ventral lobe narrow and long, weakly wide at middle and narrowing to obtuse and membranous apex; apical margin concave medially (Fig. 5D-E). Genital style in lateral view with hind margin distinctly excavated at middle (Fig. 5B). Capitulum of style narrowing to obtuse apex directing cephalad with a small blunt tooth in lateral view; in caudal view, lateral teeth thin and falcate (Fig. 5B-C).

Female Genitalia. Gonoplac with apical margin strongly convex at dorsal half; disc elevated near base in dorsal view; fork well pigmented (Fig. 5J-K). Proximal part of posterior connective lamina of gonapophyses IX slightly convex in lateral view; median field bifurcate at apex in dorsal view (Fig. 5G-H). Endogonocoxal process foliate; apex obtuse with thin setae (Fig. 5M); endogonocoxal lobe moderately long and weakly concave inward, well sclerotized (Fig. 5M). Anterior connective laminae of gonapophysis VIII broad; ventral margin straight, bearing small obtuse tooth near subapex and then concave to apex; apical group with three small teeth, and bearing a tiny tooth in opposite direction of the three teeth; lateral group with five keeled teeth (Fig. 5M). Sternum VII with apical margin distinctly arcuately convex at middle (Fig. 5L).

Neokodaiana Yang, 1994

Neokodaiana Yang in Chang \& Yang, 1994: 92 (type species: Neokodaiana chihpenensis Yang, 1994, by original designation).

\section{Note}

The monotypical genus Neokodaiana was erected for Neokodaiana chihpenensis from Taiwan by Yang in Chan \& Yang (1994). It can be diagnosed by the unique distinctly wide frons (mentioned in the key above); tegmen with wide hypocostal plate; lateral phallobasal lobes well-developed showing dorsal margin dentate near apex, with large lobe-like processes directed caudad before it; in ventral view, bearing a pair of hooks; genital style with hind margin bowl-shaped concave and apicoventral angle quadrate convex.

\section{Distribution}

China (Taiwan, Fujian).

Neokodaiana minensis Meng \& Qin, sp. nov. urn:1sid:zoobank.org:act:CFACC4FC-2E5F-4C35-BB04-D374F2911893 Figs 6-8

\section{Diagnosis}

This new species resembles $N$. chihpenensis Yang, 1994, but can be distinguished by the following combination of characters (features of $N$. chihpenensis in parentheses): 1) anal tube with large triangular projection near apex in lateral view (anal tube with the lateral projection small near apex); 2) lateral phallobasal lobes with the middle triangular lobe-like processes long, anterior margin not dentate 
MENG R. et al., Key to Issini of China and neighbouring countries

(anterior margin of the processes dentate); 3) the ventral hooks of phallobasal lobes short (the ventral hooks long, reaching nearly to apex); 4) sternite VII with posterior margin strongly widely convex at middle part (in N. chihpenensis, sternite VII with posterior margin slightly produced, truncate and curved at apex).

\section{Etymology}

The specific epithet refers to the type locality, Min, an alternative term for Fujian Province in China.

\section{Material examined}

Holotype

CHINA: 今ึ, Fujian Province, Dehua City, Shuikou Town, $118.4^{\circ}$ E, $25.7^{\circ}$ N, 12 Nov. 1974, coll. Jikun Yang.

\section{Paratypes}

CHINA: 1 ${ }^{2}, 12$ Nov. 1974, other data as for holotype; 1 क , Fujian Province, Wuyishan Mountain Sangang, 117.6 ${ }^{\circ}$ E, 27. $7^{\circ}$ N, 12 Sep. 1980, coll. Tong Chen; 1 q, Fujian Province, Daiyun Mountain, 118.2 $2^{\circ}$ E, 25.6 30 N, Aug. 1984, coll. Zhixin Cui.

\section{Measurements and ratios}

TL: $\widehat{\partial}(\mathrm{n}=2): 4.8-5.5 \mathrm{~mm}$; ㅇ $(\mathrm{n}=2): 5.1-5.6 \mathrm{~mm} ; \mathrm{LTg}: \hat{\jmath}(\mathrm{n}=2): 3.9-4.6 \mathrm{~mm}$; ㅇ $(\mathrm{n}=2): 4.1-4.6 \mathrm{~mm}$; $\mathrm{BV} / \mathrm{LV}=3.0 ; \mathrm{BF} / \mathrm{LF}=2.0 ; \mathrm{LP} / \mathrm{LV}=1.3 ; \mathrm{LM} / \mathrm{LP}=1.5 ; \mathrm{BT} / \mathrm{LM}=2.1 ; \mathrm{LTg} / \mathrm{BTg}=1.7 ; \mathrm{LA} / \mathrm{BA}($ đ $)=$ $1.7 ; \mathrm{LA} / \mathrm{BA}($ + $)=2.1$.

\section{Description}

HEAD. Vertex yellowish brown; nearly quadrangular, median carina present (Fig. 6A). Frons brown, with narrow black fascia along sublateral carina, narrow white transverse line at middle; below white line, black to fuscous; largely white along frontoclypeal suture; yellowish white tubercules inside lateral margin; median part of frons strongly convex, sublateral carinae far away from upper margin, area between them slightly oblique in lateral view (Fig. 6B-C). Genae fuscous with two white fasciae (Fig. 6B). Clypeus black brown (Fig. 6C). Eyes fuscous (Fig. 6A-B).

Thorax. Pronotum and mesonotum yellowish brown. Pronotum with median carina, anterior margin arched, posterior margin weakly concave in middle (Fig. 6A); lateral lobes relatively small, outside margin rounded (Fig. 6C). Mesonotum nearly triangular, median carina present (Fig. 6A).

TEGmen. Fuscous with yellowish brown maculae and veins. Apical margin oblique; wide hypocostal plate (Fig. 6D, see the arrow); transverse veins near apical margin almost aligned; longitudinal veins distinct; $\mathrm{ScP}+\mathrm{R}$ forking at base; $\mathrm{ScP}$ reaching beyond midlength of tegmen; $\mathrm{R}$ simple; MP forked after $\mathrm{ScP}+\mathrm{R}$; MP1 and MP2 forking near apex; $\mathrm{CuA}$ forked at apical one-third (Figs 6B, 7A).

HIND wing. Fuscous. Trilobed, but vannus and anal lobe reduced (Fig. 7B).

LEGS. Fore and median femora slightly dorso-ventrally flattened, fuscous, and yellow basally; fore and median tibiae dark brown with yellow at base; hind femur and tibia fulvous, margins fuscous, and tips of teeth black. Metatibiotarsal formula 2+12/12, 15/2.

AbDomen. Fulvous.

MALE GENITALIA. Anal tube gradually widening to subapex; apical margin obtusely convex, and emarginate in middle; in profile, subapex with large triangular projection; column moderately long, placed at middle 


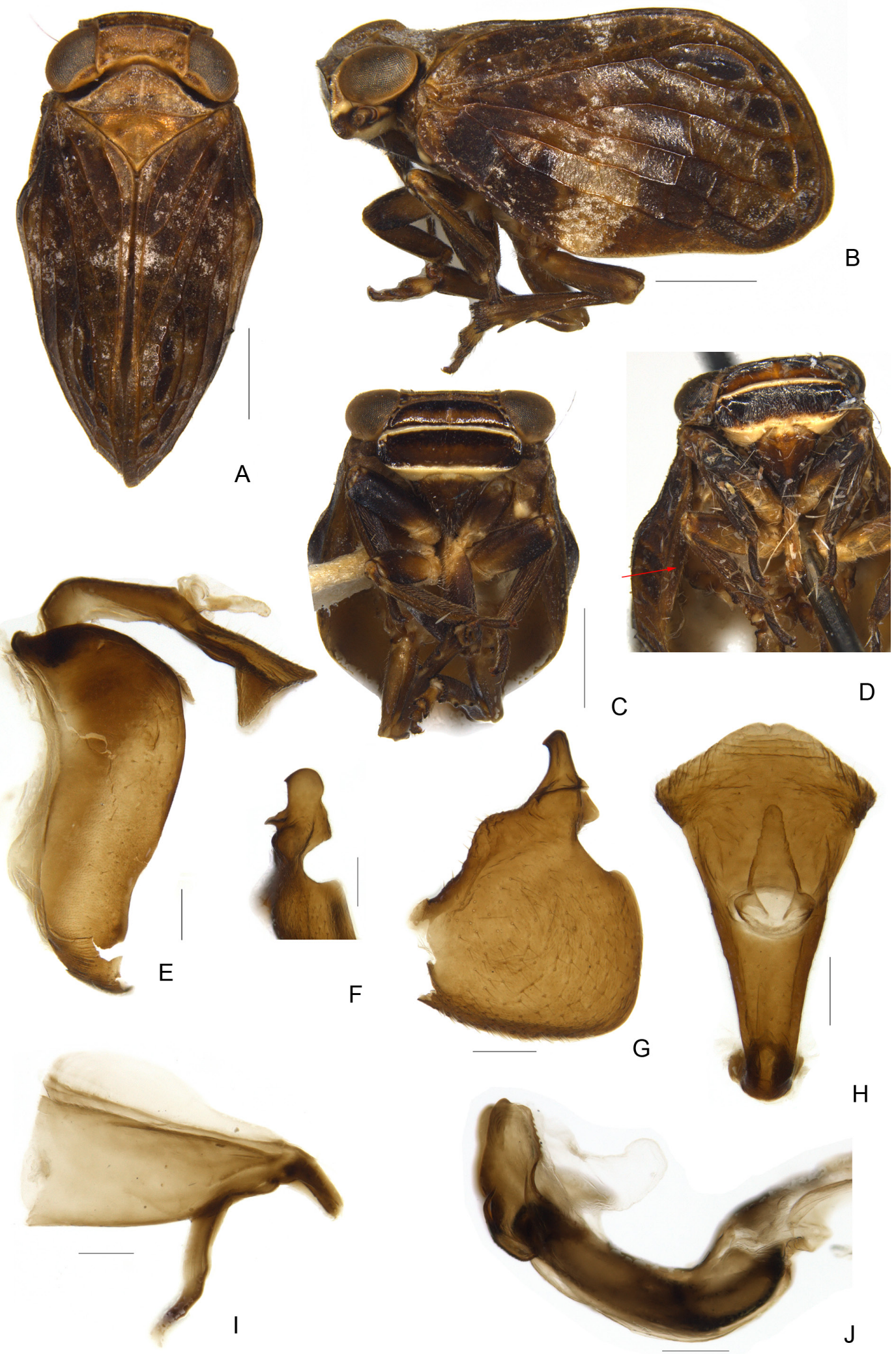

Fig. 6. Neokodaiana minensis Meng \& Qin, sp. nov., holotype. A. Habitus, dorsal view. B. Habitus, lateral view. C. Frons and clypeus. D. Head and thorax, latero-ventral view. E. Male anal tube and pygofer, lateral view. F. Capitulum of style, dorsal view. G. Gonapophyses IX and gonaspiculum bridge, right view. H. Male anal tube, dorsal view. I. Connective. J. Penis, lateral view. Scale bars $=1 \mathrm{~mm}$. 
MENG R. et al., Key to Issini of China and neighbouring countries

(Fig. 6E, H). Pygofer roundly convex at posterodorsal angle, narrowing to ventral margin (Fig. 6E). Connective strongly sclerotized, very thick and large at base (Fig. 6I). Lateral phallobasal lobes elongated and enlarged at apex; dorsal margin dentate near apex, with triangular lobe-like processes large; in ventral view, bearing a pair of short hooks, directed laterally; ventral lobe sclerotized, with apical margin blunt and curved dorsally (Figs 6J, 7C-D). Genital style relatively wide and quadrate; apical margin with deep bowl-shaped concavity below capitulum of style; dorsal margin oblique and roundly convex in middle; ventral margin moderately straight; apicoventral angle quadrate convex (Fig. 6G). Capitulum of style short, apex obtuse and spinal outside, with relatively small lateral tooth (Fig. 6F).

Female genitalia. Anal tube subrectangular in dorsal view, lateral margin subparallel, narrowing down near straight apical margin; column situated near base (Fig. 8A). Gonoplacs in profile slightly longer than wide; apical margin obtuse and membranous; in dorsal view, disc strongly elevated at basal half; fork well-sclerotized and pigmented (Fig. 8B-C). Posterior connective lamina of gonapophyses IX narrow and long, strongly convex at proximal part; median field small and single; lateral field with a pair of large teeth at level of apical margin of median field (Fig. 8D-E). Gonospiculum bridge moderately long, with basal part shorter than apical part (Fig. 8E). Anterior connective laminae of gonapophysis VIII with three very small teeth grouped apically, five small keeled grouped teeth on side (Fig. 8G). Sternite VII with posterior margin strongly widely convex at middle part (Fig. 8F).
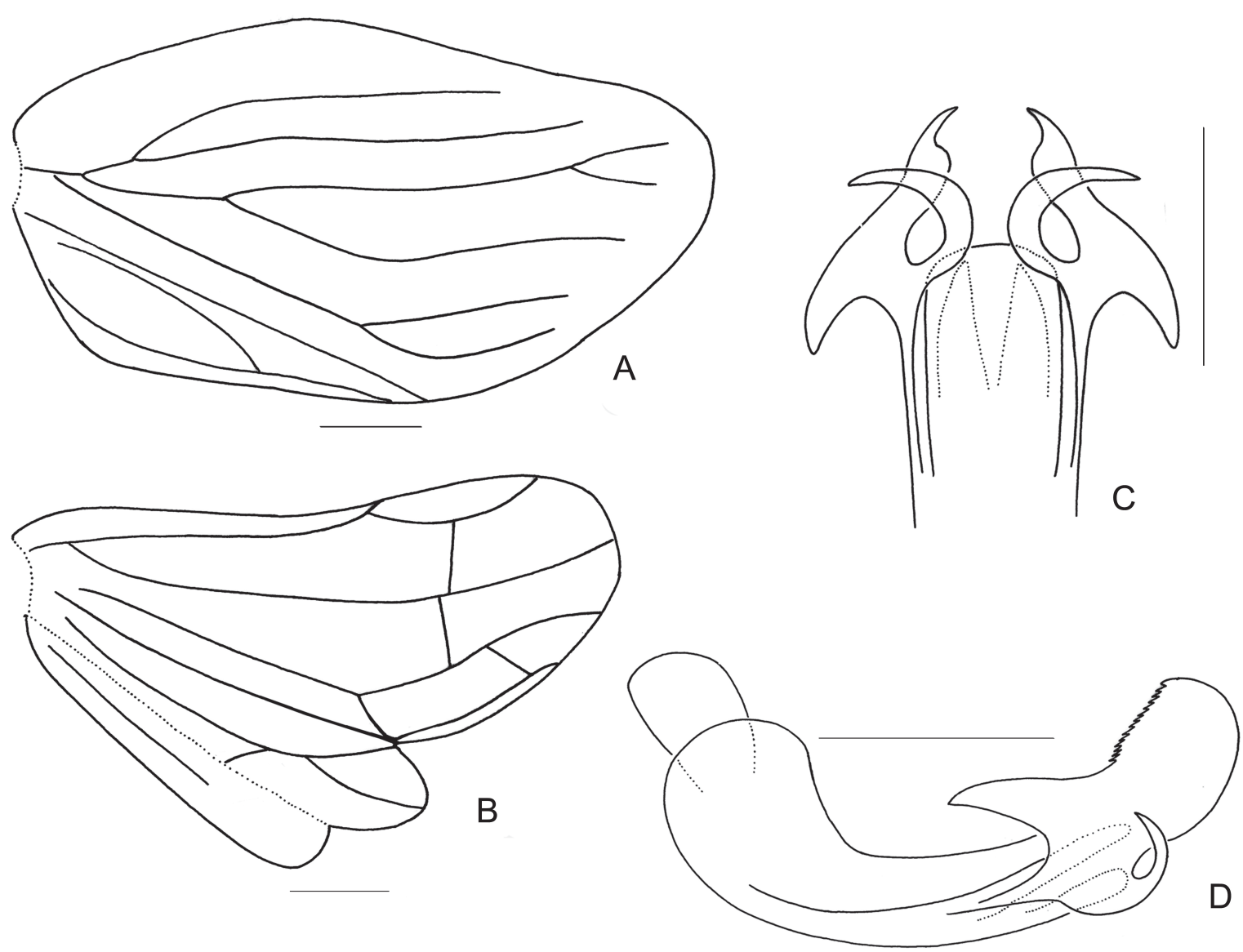

Fig. 7. Neokodaiana minensis Meng \& Qin, sp. nov., holotype. A. Tegmen. B. Hind wing. C. Penis, apical half, ventral view. D. Penis, left view. Scale bars $=0.5 \mathrm{~mm}$. 


\section{Discussion}

$O$. parallelodroma gen. et sp. nov. from southern China has two glossy rounded orbs on the frons, which are also present in Chlamydopteryx mammoides Gnezdilov \& Fletcher, 2010 from Queensland, Australia (Gnezdilov \& Fletcher 2010) and in Redarator bimaculatus Distant, 1916 from South India (Distant 1916). The presence of this special feature in these three species from different geographical locations indicates a parallel evolution. The presence of two orbs might reveal a function similar to that suggested by Constant (2005: 62) for the smooth prominences on frons of Gelastopsis insignis Kirkaldy (Hemiptera: Fulgoromorpha: Eurybrachidae) as being mimicry of the large frontal eyes of salticid spiders. Many of these spiders are of similar size to these insects and move with short jumps.

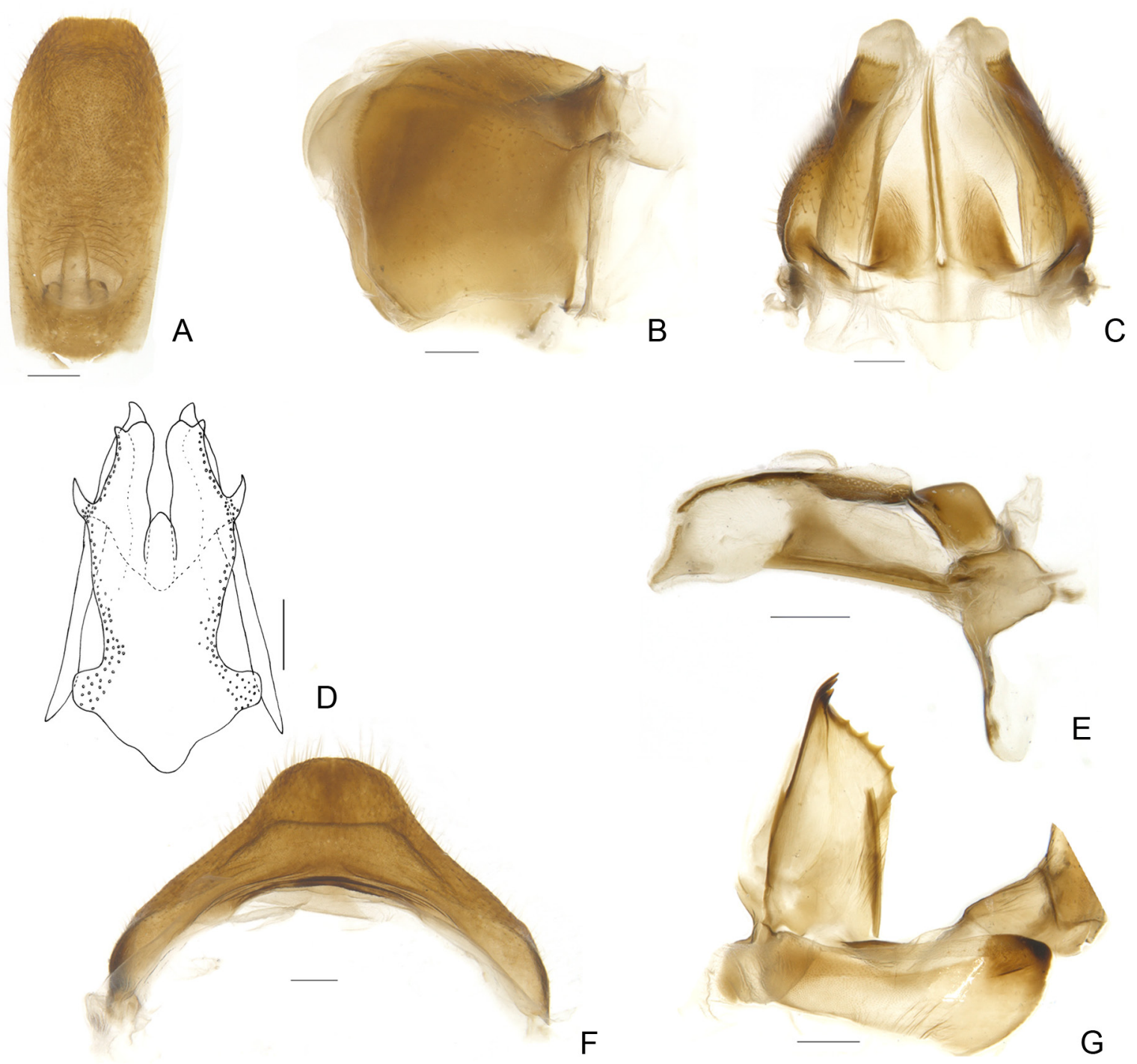

Fig. 8. Neokodaiana minensis Meng \& Qin, sp. nov. A. Female anal tube, dorsal view. B. Gonoplac, lateral view. C. Gonoplac, dorsal view. D. Gonapophyses IX and gonaspiculum bridge, dorsal view. E. Gonapophyses IX and gonaspiculum bridge, right view. F. Sternum VII, ventral view. G. Gonocoxa VIII and gonapophysis VIII, right view. Scale bars $=0.2 \mathrm{~mm}$. 
MENG R. et al., Key to Issini of China and neighbouring countries

\section{Acknowledgements}

We are sincerely grateful to Prof. Murray J. Fletcher (Orange Agricultural Institute, NSW Department of Primary Industry, Australia) and Prof. John Richard Schrock (Department of Biological Sciences, Emporia State University, USA) for proof-reading the manuscript. This study is supported by the National Natural Science Foundation of China (31372234, 30970388) and Fauna Sinica (2006FY120100) under the Ministry of Science and Technology of China.

\section{References}

Anufriev G.A. \& Emeljanov A.F. 1988. Suborder Cicadinea (Auchenorrhyncha). In: Ler P.A. (eds) Keys to the Insects of the Far East of the USSR 2: 12-495. Nauka, Leningrad.

Bonfils J., Attié M. \& Reynaud B. 2001. Un nouveau genre d'Issidae de l'île de la Réunion: Borbonissus n. gen. (Hemiptera, Fulgoromorpha). Bulletin de la Société Entomologique de France 106: 217-224.

Bourgoin T. 1993. Female genitalia in Hemiptera Fulgoromorpha, morphological and phylogenetic data. Annales de la Société Entomolologique de France 29 (3): 225-244.

Bourgoin T., Wang R.-R., Asche M., Hoch H., Soulier-Perkins A., Stroiński A., Yap S. \& Szwedo J. 2014. From micropterism to hyperpterism: recognition strategy and standardized homologydriven terminology of the forewing venation patterns in planthoppers (Hemiptera: Fulgoromorpha). Zoomorphology 134 (1): 63-77. http://dx.doi.org/10.1007/s00435-014-0243-6

Bourgoin T. 2015. FLOW (Fulgoromorpha Lists on The Web): a world knowledge base dedicated to Fulgoromorpha. Version 8, updated Available from http://hemiptera-databases.org/flow/ [accessed on 6 Nov. 2015].

Chan M.-L. \& Yang C.-T. 1994. Issidae of Taiwan (Homoptera: Fulgoroidea). Chen Chung Book Press, Taichung.

Che Y., Zhang Y.-L.\& Wang Y.-L. 2011. A new genus of the tribe Issini Spinola (Hemiptera: Fulgoroidea: Issidae) from China. Zootaxa 3060: 62-66.

Che Y.-L., Zhang Y.-L. \& Wang Y.-L. 2012. A new genus of the tribe Issini Spinola (Hemiptera: Fulgoroidea: Issidae) from China. ZooKeys 228: 51-57. http://dx.doi.org/10.3897/zookeys.228.3465

Chen X.-S., Zhang Z.-G. \& Chang Z.-M. 2014. Issidae and Caliscelidae (Hemiptera: Fulgoroidea) from China. Guizhou Science and Technology Publishing House, Guiyang.

Chou I., Lu J.-S., Huang J. \& Wang S.-Z. 1985. Economic Insect Fauna of China, Fasc. 36, Homoptera Fulgoroidea. Science Press, Beijing, China.

Constant J. 2004. Révision des Eurybrachidae (I). Le genre Amychodes Karsch, 1895 (Homoptera: Fulgoromorpha: Eurybrachidae). Bulletin de l'Institut royal des Sciences naturelles de Belgique 74: $11-28$.

Constant J. 2005. Revision of the Eurybrachidae (IV). The Australian genus Gelastopsis Kirkaldy, 1906 (Hemiptera: Fulgoromorpha: Eurybrachidae). Bulletin de l'Institut royal des Sciences naturelles de Belgique, Entomologie 75: 57-69.

Distant W.L. 1906. The Fauna of British India, Ceylon and Burma. Rhynchota (Heteroptera-Homoptera) 3. Taylor \& Francis, London.

Distant W.L. 1916. The Fauna of British India Including Ceylon and Burma. Rhynchota. Homoptera: Appendix. 4. Taylor \& Francis, London.

Emeljanov A.F. 1971. New genera of leafhoppers of the families Cixiidae and Issidae (Homoptera, Auchenorrhyncha) from the fauna of the USSR. Entomological Review 50 (3): 619-627. 
Eskai T. 1931. Undescribed Hemiptera from Japan and Formosa. Annotationes Zoologicae Japonenses 13: $259-269$.

Fennah R.G. 1956. Fulgoroidea from southern China. Proceedings of the California Academy of Sciences 28 (4): 441-527. http://biodiversitylibrary.org/page/15656827

Fennah R.G. 1978. Fulgoroidea (Homoptera) from Vietnam. Annales Zoologici Warszawa 34 (9): 63267.

Gnezdilov V.M. 2009. Revisionary notes on some tropical Issidae and Nogodinidae (Hemiptera: Fulgoroidea). Acta Entomologica Musei Nationalis Pragae 49 (1): 75-92.

Gnezdilov V.M. 2010. Three new genera and three new species of the family Issidae (Hemiptera: Fulgoromorpha) from Borneo and Sumatra. Tijdschrift voor Entomologie 153: 41-52.

Gnezdilov V.M. 2012. On the taxonomy of some Fulgoroidea (Hemiptera). Proceedings of the Zoological Institute RAS 316 (3): 239-247.

Gnezdilov V.M. 2013a. Modern classification and distribution of the family Issidae Spinola (Homoptera, Auchenorrhyncha: Fulgoroidea). Entomologicheskoe obozrenie 92 (4): 724-738. English translation published in Entomological Review 94 (5): 687-697. http://dx.doi.org/10.1134/S0013873814050054

Gnezdilov V.M. 2013b. Notes on the genus Sarima (Hemiptera: Fulgoroidea: Issidae) with description of a new genus from Sri Lanka. Acta Musei Moraviae, Scientiae Biologicae (Brno) 98 (2): 175-182.

Gnezdilov V.M. 2013c. On the genera Sivaloka Distant, 1906 and Kodaianella Fennah, 1956 (Hemiptera: Fulgoroidea: Issidae). Deutsche Entomologische Zeitschrift 60 (1): 41-44.

Gnezdilov V.M. 2014. Review of Indochinese Issini Spinola, 1839 (Hemiptera, Fulgoroidea, Issidae), with description of a new genus from Laos. Zoosystema 36 (4): 761-770. http://dx.doi.org/10.5252/ z2014n4a4

Gnezdilov V.M. \& Constant J. 2012. Review of the family Issidae (Hemiptera: Fulgoromorpha) in Vietnam with description of a new species. Annales Zoologici (Warszawa) 62 (4): 571-576. http:// dx.doi.org/10.3161/000345412X659632

Gnezdilov V.M. \& Fletcher M.J. 2010. A review of the Australian genera of the planthopper family Issidae (Hemiptera: Fulgoromorpha) with description of an unusual new species of Chlamydopteryx Kirkaldy. Zootaxa 2366: 35-45.

Gnezdilov V.M. \& Hayashi M. 2013. New Synonyms of Sarimodes taimokko Matsumura, 1916 (Hemiptera, Fulgoroidea, Issidae). Formosan Entomologist 33: 161-165.

Gnezdilov V.M. \& Wilson M.R. 2006. Systematic notes on tribes in the family Caliscelidae (Hemiptera: Fulgoroidea) with the description of new taxa from Palaearctic and Oriental Regions. Zootaxa 1359: $1-30$.

Gnezdilov V.M., Bourgoin T. \& Soulier-Perkins A. 2014a. Vietnamese Issidae (Hemiptera, Fulgoroidea): new taxa, new records and new distribution data. Zootaxa 3847 (1): 80-96. http://dx.doi.org/10.11646/ zootaxa.3847.1.4

Gnezdilov V.M., Drosopoulos S. \& Wilson M.R. 2004. New data on taxonomy and distribution of some Fulgoroidea (Homoptera, Cicadina). Zoosystematica Rossica 12 (2): 217-223.

Gnezdilov V.M., Holzinger W.E. \& Wilson M.R. 2014b. The Western Palaearctic Issidae (Hemiptera, Fulgoroidea): an illustrated checklist and key to genera and subgenera. Proceedings of the Zoological Institute RAS, 318 (Supplement 1): 1-124. 
MENG R. et al., Key to Issini of China and neighbouring countries

Gnezdilov V.M., Le Cesne M.L., Soulier-Perkins A. \& Bourgoin T. 2015. New Guinean Issidae: description of new taxa in a poorly known island fauna (Hemiptera, Fulgoroidea). Zootaxa 3904 (1): 82-94. http://dx.doi.org/10.11646/zootaxa.3904.1.4

Jacobi A. 1944. Die Zikadenfauna der Provinz Fukien in Südchina und ihre tiergeographischen Beziehungen. Mitteilungen der Münchener Entomologischen Gesellschaft 34: 5-66. http:// biodiversitylibrary.org/page/29138439

Kato M. 1933. Notes on Japanese Homoptera, with descriptions of one new genus and some new species. Entomological World 1: 452-471.

KirkaldyG. W. 1904. Bibliographical and nomenclatorial notes on the Hemiptera No3. Entomologist (London) 37: 279-283.

Matsumura S. 1916. Synopsis der Issiden (Fulgoriden) Japans. Transactions of the Shikoku Entomological Society 6 (2): 85-118.

Matsumura S. 1938. Homopterous insect collected by Mr. Tadao Kano at Kotosho, Formosa. Insecta Matsumurana 12 (4): 147-153.

Melichar D.L. 1903. Homopteren-Fauna von Ceylon. F.L. Dames, Berlin.

Melichar D.L. 1906. Monographie der Issiden (Homoptera). Abhandlungen der Kaiserlich-Königlichen Zoologisch-Botanischen Gesellschaft in Wien 3: 1-327.

Melichar D.L. 1907. Bemerkungen zur Monographie der Issiden (Homoptera). Wiener Entomologische Zeitung 26: 323-324.

Meng R. \& Wang Y.-L. 2012. Two new species of the genus Celyphoma Emeljanov, 1971 (Hemiptera: Fulgoromorpha: Issidae) from China. Zootaxa 3497: 17-28.

Schumacher F. 1915. Homoptera in H. Sauter's Formosa-Ausbeute. Supplementa Entomologica 4: 108 142 .

Stål C. 1861. Nova methodus familias quasdam Hemipterorum disponendi. Öfversigt af Kongliga Vetenskaps Akademiens Förhandlingar 18: 195-223.

Stål C. 1866a: Hemiptera Homoptera Latr. Hemiptera Africana 4: 1-276. http://dx.doi.org/10.5962/bhl. title. 8566

Stål C. 1866b. Analecta hemipterologica (continuatio). Berliner Entomologische Zeitschrift 10: 381394. http://biodiversitylibrary.org/page/ 8340513

Walker F. 1851. List of the Specimens of Homopterous Insects in the Collection of the British Museum, 2. Natural History Museum Order of Trustees, London.

Manuscript received: 11 July 2015

Manuscript accepted: 10 November 2015

Published on: 14 March 2016

Topic editor: Koen Martens

Desk editor: Kristiaan Hoedemakers

Printed versions of all papers are also deposited in the libraries of the institutes that are members of the EJT consortium: Muséum national d'Histoire naturelle, Paris, France; Botanic Garden Meise, Belgium; Royal Museum for Central Africa, Tervuren, Belgium; Natural History Museum, London, United Kingdom; Royal Belgian Institute of Natural Sciences, Brussels, Belgium; Natural History Museum of Denmark, Copenhagen, Denmark. 